\title{
Interactive comment on "Is there a direct solar proton impact on lower stratospheric ozone?" by Jia Jia et al.
}

\section{Anonymous Referee \#1}

Received and published: 8 June 2020

In this paper, the impact of solar proton events on ozone in the high-latitude $\left(60-90^{\circ} \mathrm{N}\right)$ lower stratosphere below $30 \mathrm{~km}$ altitude is investigated bases on MLS observations and model simulations with the WACCM-D model. It is well known that large solar proton events can have a large impact on atmospheric composition, particularly on NOx, HOx and ozone, in the upper stratosphere and mesosphere above $40 \mathrm{~km}$ altitude, but little evidence has been provided so far for an impact on the stratosphere below $30 \mathrm{~km}$; the data shown in this study provide interesting new insight in this field. The paper is well structured and well written.

However, unfortunately in my opinion the main conclusion provided in this paper is not sufficiently supported by the results shown.

The main conclusion is that "the SPE has a zero direct impact on the lower strato- 
spheric ozone" (line 20 of the abstract). This is a very strong conclusion. My opinion that it is not sufficiently supported by the results is based on three things: a) while the authors show that some of the observed anomalies in 10-20 km altitude are likely due to other forcings not SPEs, there are some cases where negative anomalies at and below $20 \mathrm{~km}$ occur, but no other forcings besides proton ionization are identified. This is particulary true for the ground-level event of January 2005 which had exceptionally high fluxes at high particle energies. Further analyses are clearly needed before a clear conclusion can be drawn on this. b) the lower stratosphere is affected directly only by protons with energies larger then $200 \mathrm{MeV}$, but the analysis is based on fluxes of protons with energies $>10 \mathrm{MeV}$, which are relevant in the mid- and lower mesosphere below $70 \mathrm{~km}$. c) the model results are based on proton fluxes $>300 \mathrm{MeV}$ which affect the atmosphere above $25 \mathrm{~km}$ altitude (see further comments and references below); no conclusions can be drawn from these model runs about a possible direct impact of proton ionization below $25 \mathrm{~km}$ altitude.

Therefore, the authors either need to carry out further analyses of their data (some suggestions are provided in my specific comments below), or formulate their conclusions much more carefully.

\section{Specific comments:}

Title and page 1, line 11: on lower stratospheric ozone depletion. I would say that "lower stratosphere" would mean tropopause (8-12 km) to about 20-25 km. However lower stratosphere is not a well-defined term, so just clarify in this sentence which altitudes you focus on (10-30 km?)

Page 2, line 12 "most advanced climate models are now including EPP forcing" better change this to "many advanced chemistry-climate models ..." because a) I doubt that this is really done by "most" models, and b) you need atmospheric chemistry to include EPP forcing. Climate models include atmospheric dynamics and ocean coupling, but not necessarily interactive atmospheric chemistry. The term is either chemistry-climate

Printer-friendly version

Discussion paper
Interactive

comment

\section{2}


model or composition-climate model to clarify that you need atmospheric chemistry as well.

Page 2, line 14: please provide a reference for $\sim 10 \%$ alpha

Page 2, line 15 and 16: ... tens to hundreds of MeV . . at altitudes of 35 âĂŤ $90 \mathrm{~km}$ .... I think what you mean is that solar proton events affect the atmosphere mainly in the altitude region of $35 \hat{A} A$ Ť $90 \mathrm{~km}$, but what you say is that protons and alpha of $10-1000 \mathrm{MeV}$ mainly deposit their energy in $35 \hat{A} \hat{A}$ Ť90 km. This is not correct. Protons with energies of $10 \mathrm{MeV}$ release most of their energy around $70 \mathrm{~km}$, protons with

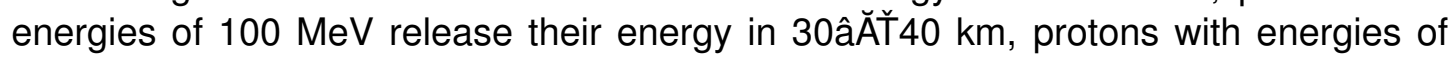
$1000 \mathrm{MeV}$ release their energy below $20 \mathrm{~km}$ (Turunen et al., 2009, Fig 3; Wissing and Kallenrode, 2009, Fig. 2). Soft protons and electrons may also contribute to affect altitudes above $70 \mathrm{~km}$, and the fluxes of protons larger than $100 \mathrm{MeV}$ are low in many solar proton events, though events with a very hard spectrum, with large fluxes of $>$ $100 \mathrm{MeV}$ protons, exist. One example is the very strong ground-level enhancement of January 2005 (e.g., Jackman et al., 2011, see also Table 1 in Gopalswamy et al., 2005). Please be more precise.

Page 2, Line 25 "large events", and line 27 "very extreme events", please specify what you mean by those terms. Presumably fluxes of protons at, or larger than, some specified energy range.

Page 3, line 22: $300 \mathrm{MeV}$ protons mostly affect the altitude range around $25 \mathrm{~km}$ (Turunen et al., 2009; Wissing and Kallenrode, 2009). As $300 \mathrm{MeV}$ is the upper limit of proton energies considered in your model runs, you can therefore only investigate the impact of direct proton forcing at altitudes above $\sim 25 \mathrm{~km}$. As you don't implement proton energies able to reach altitudes below $25 \mathrm{~km}$, you can not make any statements on the impact of proton ionization on altitudes below $25 \mathrm{~km}$ based on these model experiments. You could presumably use the model experiments to investigate possible dynamical feedbacks onto the lower stratosphere below $25 \mathrm{~km}$ to proton ionization 
above this altitude though. Page 3, line 27-30: ... protons $>300 \mathrm{MeV}$ are not included .. as the contribution of $>300 \mathrm{MeV}$ protons to direct ozone loss ... would likely be negligible due to the small fluxes at such high energies ... to summarize: you don't include those proton energies because they likely have no impact, do model experiments without those proton energies, analyse the model experiments, and conclude that there is no impact in those altitudes? That is circular reasoning. See my comment above: you can not draw any conclusions of a direct impact of proton ionization on altitudes below $25 \mathrm{~km}$ on the basis of these model experiments.

Page 4, Figure 1: the figure caption states that ionization rates used for this figure are derived at $1 \mathrm{hPa}$, that is, about $45 \mathrm{~km}$ - around the stratopause. If you want to investigate the impact of those events on the lower stratosphere below $30 \mathrm{~km}$ altitude, this is not a very useful quantity. Ionization rates at $10 \mathrm{hPa}(\sim 30 \mathrm{~km})$ or even lower would be much more relevant here. I would suggest that you either exchange this figure with $10 \mathrm{hPa}$, or show both $10 \mathrm{hPa}$ and $1 \mathrm{hPa}$.

Page 4, line 20, and page 3, line 35: the SPE onset time is defined as the time when 5 -min average proton fluxes with energies $>10 \mathrm{MeV}$ are greater than $10 \mathrm{pfu}$. Why base the analysis on protons of comparably low energies ( $10 \mathrm{MeV}$ protons mainly affect $\sim 70$ $\mathrm{km}$ altitudes, see above) if you want to analyse the impact on the lower stratosphere below $30 \mathrm{~km}$ ? > $100 \mathrm{MeV}$ would be more relevant. Even if you argue that you do not want to exclude soft-spectrum SPEs with large fluxes, the onset time of the event may vary for different energies.

Page 5, line 13-14: the spatial distribution of events is similar in summer and winter, but the amplitudes are larger during winter. This may also be a purely statistical effect due to the much lower number of events (19 compared to 49), as outliers have a larger impact in small sample sizes.

Page 5, line 24: "the signatures above and below are not related to the epoch time" what you actually see is that the signatures already appear a considerable time before

Printer-friendly version

Discussion paper
Interactive

comment 
the event. So you argue that they are not related to the event. This is not necessarily true. Solar proton events are not completely isolated events. There often are series of solar proton events separated by a few (up to 27) days, as clearly seen, e.g., in Figs. $3, A 2$ and A3. If the first event in a series is strong, then the superposed epoch gives a response before the event. You can clearly see this in the right panel of Figure 2 at $60-70 \mathrm{~km}$. Solar proton events are also often preceded by strong flares which may or may not have an impact on the atmosphere, and occur during periods of strong geomagnetic activity, with geomagnetic storms before, during or after the event. You can't exclude a significant response solely on the basis of the timing alone.

Page 6, line 3-4: However, there was no robust ozone loss below $30 \mathrm{~km}$ in the WACCM$\mathrm{D}$ simulations; considering the limit of proton energies in the model experiments, one would not expect a direct impact of proton ionization in these model results below $25 \mathrm{~km}$. However, the WACCM-D simulations could be used to analyse the observed response of MLS ozone in a more rigorous way, by doing the analysis of WACCMD ozone with exactly the same sampling as done in MLS data - that is using the same number of events, and the same time-period for the baseline annual cycle. As WACCM-D is runs are carried out in the specified dynamics mode, any dynamical variations of ozone including ozone hole chemistry, should be reproduced by the model very well, but any direct proton impacts below $25 \mathrm{~km}$ would not be reproduced at all, so significant differences between model and MLS response might indicate a direct proton impact. However, if results are very similar, this would indicate no significant (on average) proton impact. This would provide a more rigorous test also than comparing the individual events in the Appendix figures, and I urge the authors to do such an analysis.

Page 6, lines 6-7: Despite the fact that WACCM-D epoch analysis ... around $20 \mathrm{~km} \ldots$ it is a good idea to look at individual events, but that there is no response of WACCM-D results at $20 \mathrm{~km}$ is the totally wrong argument here, because WACCM-D only includes proton energies $>300 \mathrm{MeV}$. A better argument would be the low number of events, and

Printer-friendly version

Discussion paper
Interactive

comment 
high variability of stratospheric ozone, influenced, e.g., also by SSWs or heterogeneous chemistry on PSC surfaces, particularly during winter. Please rewrite this sentence accordingly.

Page 6, section 4 and Figures 3, 4: you select events here based on large proton fluxes $>10 \mathrm{MeV}$. However, if you really want to look at impacts on the lower stratosphere, it would make more sense to select for $>300 \mathrm{MeV}$ fluxes. You could also select for ground-level events, however, based on the list provided by Gopalswamy et al 2005, this would presumably leave you with a list of 1 in the MLS time-period - January 2005, which really seems to have been exceptional (is there an update for 2005-now?).

Page 6, line 17-18: if you want to compare the variation in the MLS and WACCM-D events, it would be better to use the same period - the MLS data period - for both MLS and WACCM-D. Else differences in the anomalies might also be due to differences in the background period.

Page 7, line 6 to page 8, line 16: this analysis on the reasons for strong ozone anomalies not related to SPEs is very useful and concise. I also agree to your conclusion as stated in lines 15-16 of page 8 , that these variations contribute to the robust anomalies below $30 \mathrm{~km}$ as seen in Fig. 2. In particular, the significant negative ozone anomaly in 10-30 km starting well before the event onset is clearly influenced strongly by the anomalously cold late winter/spring in early 2011 , whose impact on lower stratospheric ozone is well documented (e.g., Sinnhuber et al., 2011). However, I think you should go one step further and redo the superposed epoch analysis excluding those events in cold winters (that is, in winter 2010/2011, 2015/2016 and 2019/2020), and also those events where an SSW occurred within the epoch period. While this would reduce the number of events, it would also reduce the background variability, and thus hopefully provide more robust results.

Page 9, lines 11-14: you should stress here that the MLS anomalies you observe are (contrary to the analysis in Jackman et al 2011) not due to seasonal changes. The

Printer-friendly version

Discussion paper
Interactive

comment 
changes you observe during and after the January 2005 GLE may be unique within the MLS timeseries; however, so apparently is the event itself, at least in terms of the highest energies (compare to Tab 1 in Gopalswamy et al 2005). It may be comparable in terms of the $>10 \mathrm{MeV}$ fluxes compared to the Oct-Nov 2003 SPEs, but in terms of the highest energies, fluxes were apparently much larger - more than an order of magnitude in terms of the GLE intensity. So the ozone changes observed during this event below $20 \mathrm{~km}$ altitude might indicate that ozone losses related to SPEs in these altitudes may be possible for events with very hard spectra (GLEs). I agree with you that more research needs to be done on this before a robust conclusion can be drawn on this, but I don't think you can dismiss this on the basis that no other event shows something similar. It appears to be a fairly unique event.

Page 9, lines 36-39: I do not agree that you can draw the conclusion that "bases on our analysis ... SPE do not cause direct lower stratospheric ozone anomalies" based on the evidence you have provided. I agree that you provided evidence that some of the significant negative ozone anomalies are not due to a direct ozone impact but to other forcings, most obviously in March 2011. However, you do not provide a similar convincing explanation for the January 2005 event, which was exceptional in containing a very hard spectrum, and thus provides the most likely candidate of an impact on the lower stratosphere from the events sampled here. This of course does not prove that such an impact exists for very hard spectra ground-level events in general, or even during this event. However, you can't just disregard it, either; there clearly is a need for further analysis on this topic. You can conclude that solar proton events with large fluxes at $>10 \mathrm{MeV}$ do not necessarily provide a large impact below $30 \mathrm{~km}$ altitude, if they don't have a very hard spectrum with high fluxes at $>200 \mathrm{MeV}$ as well. However, you can't say anything definite about hard-spectra solar proton events here because you did not explicitly test for this.

Turunen et al., Impact of different energies of precipitating particles on NOx generation in the middle and upper atmosphere during geomagnetic storms, JASTP, 71, 1176- 
Wissing, J.M. and Kallenrode, M., Atmospheric Ionization Module Osnabrueck (AIMOS), J. Geophys. Res., 114, doi: 10.1029/2008JA013884, 2009.

Jackman, C.H., et al., Northern hemisphere atmospheric influence of solar proton events and ground level enhancement in January 2005, Atmos. Chem. Phys., 11, 6153-6166, 2011

Gopalswamy, N., et a., Coronal mass ejections and ground level enhancements, 29th Cormic Ray Conference Pune, India, 1, 101-104, August 2005

Sinnhuber, B.-M., et al., Arctic winter 2010/2011 at the brink of an ozone hole, GRL, 38, https://doi.org/10.1029/2011GL049784, 2011

Interactive comment on Atmos. Chem. Phys. Discuss., https://doi.org/10.5194/acp-2020-273, 2020. 